\title{
2006-203: A HANDS-ON, INTERDISCIPLINARY LABORATORY PROGRAM AND EDUCATIONAL MODEL TO STRENGTHEN A RADAR CURRICULUM FOR BROAD DISTRIBUTION
}

\section{Mark Yeary, University of Oklahoma}

Dr. Mark Yeary is an Assistant Professor in the School of Electrical and Computer Engineering at the University of Oklahoma. He has many years of experience as a teaching assistant, lecturer, and assistant professor. Since January of 1993, he has taught many students in various laboratories and lecture courses, culminating in approximately 11 years of teaching experience. For the 1999-00 academic year, he received the Outstanding Professor Award, given by the Texas A\&M student chapters of IEEE and Eta Kappa Nu, and IBM in Austin. His research and teaching interests are in the areas of customized embedded DSP systems and digital signal processing as applied to radar signal processing, digital communications, image processing, adaptive filter design, and real-time systems. His applied signal processing contributions are many, and include the design an all-digital system-on-a-chip scheme for a Ka band radar and various target tracking algorithm developments for phased array systems.

\section{Tian Yu, University of Oklahoma}

Dr. Tian-You Yu is an Assistant Professor in the School of Electrical and Computer Engineering. His education at the University of Nebraska and post-doc experience at the National Center for Atmospheric Research in Boulder, Colorado provide a unique cross-disciplinary background of atmospheric research. He has many reviewed technical journal and conference papers in the areas of applications of signal processing techniques to radar problems and studies using atmospheric radars. In parallel with his technical strength, he has a passion for delivering high quality education. He has developed and taught several undergraduate and graduate courses at the University of Oklahoma.

\section{Robert Palmer, University of Oklahoma}

Dr. Robert Palmer has published extensively in the general area of radar remote sensing of the atmosphere, with emphasis on the use of multiple frequencies/receivers for interferometry and generalized imaging problems. His has taught courses from the freshman to the graduate level in signals and systems, random processes, and weather radar for 13 years. He has won the University of Nebraska-Lincoln (UNL) College of Engineering Faculty Teaching Award and has twice been recognized by the UNL Teaching Council for contributions to students. Prof. Palmer moved to the University of Oklahoma (OU) in the summer of 2004. After coming to OU, he led the development of a cross-disciplinary curriculum in weather radar and instrumentation between the School of Meteorology and the School of Electrical and Computer Engineering. This program has seen heavy enrollments since its inception and is currently expanding and evolving to meet the needs of both undergraduate and graduate students.

\section{Mike Biggerstaff, University of Oklahoma}

Dr. Michael Biggerstaff is the lead scientist behind the Shared Mobile Atmospheric Research and Teaching (SMART) radar program, a collaborative effort between the University of Oklahoma, Texas A\&M University, Texas Tech University, and the National Severe Storms Laboratory that built and successfully deployed two mobile radars to enhance storm research and to improve meteorological education. Dr. Biggerstaff has received awards in teaching and advising. He received several invitations for short courses in the U.S. and abroad.

\section{Fink, University of Oklahoma}

Dr. L. Dee Fink, an off-campus evaluator, is the person responsible for developing and implementing the evaluation plan, and he has an extensive background in pedagogy and assessment. Because of this expertise, Dr. Fink will be responsible for: 1.) developing and 
monitoring the pedagogical models being used, 2.) leading the orientation programs for both undergraduate peer teachers and the faculty members involved, to make sure they fully understand the pedagogy procedures being used, 3.) developing the evaluation plan and materials, 4.) collecting and analyzing the evaluation data.

\section{Carolyn Ahern, Ahern and Associates}

Dr. Carolyn Ahern, Assessment Coordinator, earned her B.A. in English from Ohio Wesleyan and her M.A. and Ph.D. in English from Cornell University. She also holds an M.B.A. from the University of Oklahoma. For the last 20 years, she has specialized in the design, implementation, and assessment of educational materials. Most recently, she has been the coordinator of assessment for two NSF grants at the University of Oklahoma: Sooner City (Civil and Environmental Engineering) and the Course, Curriculum, and Laboratory Improvement Project (the School of Electrical and Computer Engineering and the School of Meteorology). 


\section{A Hands-on, Interdisciplinary Laboratory Program and Educational Model to Strengthen a Radar Curriculum for Broad Distribution}

\section{Introduction}

Severe and hazardous weather such as thunderstorms, downbursts, and tornadoes can take lives in a matter of minutes. In order to improve detection and forecast of such phenomena using radar, one of the key factors is fast scan capability. Conventional weather radars, such as the ubiquitous NEXRAD (Next Generation Radar developed in the 1980's), are severely limited by mechanical scanning. Approximately 175 of these radars are in a national network to provide the bulk of our weather information.

Under the development for weather applications, the electronically steerable beams provided by the phased array radar at the NWRT can overcome these limitations of the current NEXRAD radar. For this reason, the phased array radar was listed by the National Research Council as one of the primary candidate technologies to supersede the NEXRAD [1]. By definition, a phased array radar is one that relies on a two-dimensional array of small antennas. Each antenna has the ability to change its phase characteristics, thus allowing the overall system to collectively locate specific interesting regions of weather. The NWRT is the nation's first facility dedicated to phased array radar meteorology. In addition, the demand for students trained in this area will be high as new radar technologies replace the ones designed 20 years ago, and as weather radar usage extends into areas such as homeland security. From the Federal Aviation Administration's (FAA) perspective, the phased array radar technology developed at the NWRT will be used to enhance the safety and capacity of the National Airspace System. Moreover, this proposal is consistent with one of NOAA's Mission Goals for the $21^{\text {st }}$ Century: to serve society's needs for weather information [2].

Long-term warnings have improved greatly over the last five years and are now being used for critical decision making [3]. Further improvements are being aimed at providing longer warning lead times before severe weather events, better quantification of forecast uncertainties in hurricanes and floods, and tools for integrating probabilistic forecasts with other data sets. Many other industries, groups, and individuals use weather information. For example, the construction industry uses weather information to schedule specific activities and to purchase materials. K-12 teachers use weather data to develop math and engineering skills in their students, which is essential for the future $[4,5,6]$.

Following the classic Boyer Report, it is very important that no gap exists between teaching and research [7]. In addition, faculty members who creatively combine teaching with research are essential to the improvement of undergraduate education $[8,9,10,11]$. With this in mind, we now introduce the model that governs and sustains the teaching and research mission of our university laboratory, as depicted in Figure 1. The synergistic interaction between teaching and research, their drivers and end-results is also illustrated. These drivers can be classified into those of resource needs (e.g. qualified personnel) and technology related issues. Resource needs can be further classified into three types - (1) design and application engineers, (2) radar system integrators and managers, and (3) research and development scientists. These needs 
are met by BS, MS, and PhD graduates, respectively. Thus our undergraduate and graduate educational initiatives have been developed to provide an appropriate level of training at the BS, MS, and PhD levels in this lab. The foundational key to the entire endeavor is the undergraduate educational process - these students are the first ones to enter our cycle that stresses lifelong learning, creativity, global awareness, and interdisciplinary collaborations. Sharing exciting projects with students will occur naturally here, since the authors have col-

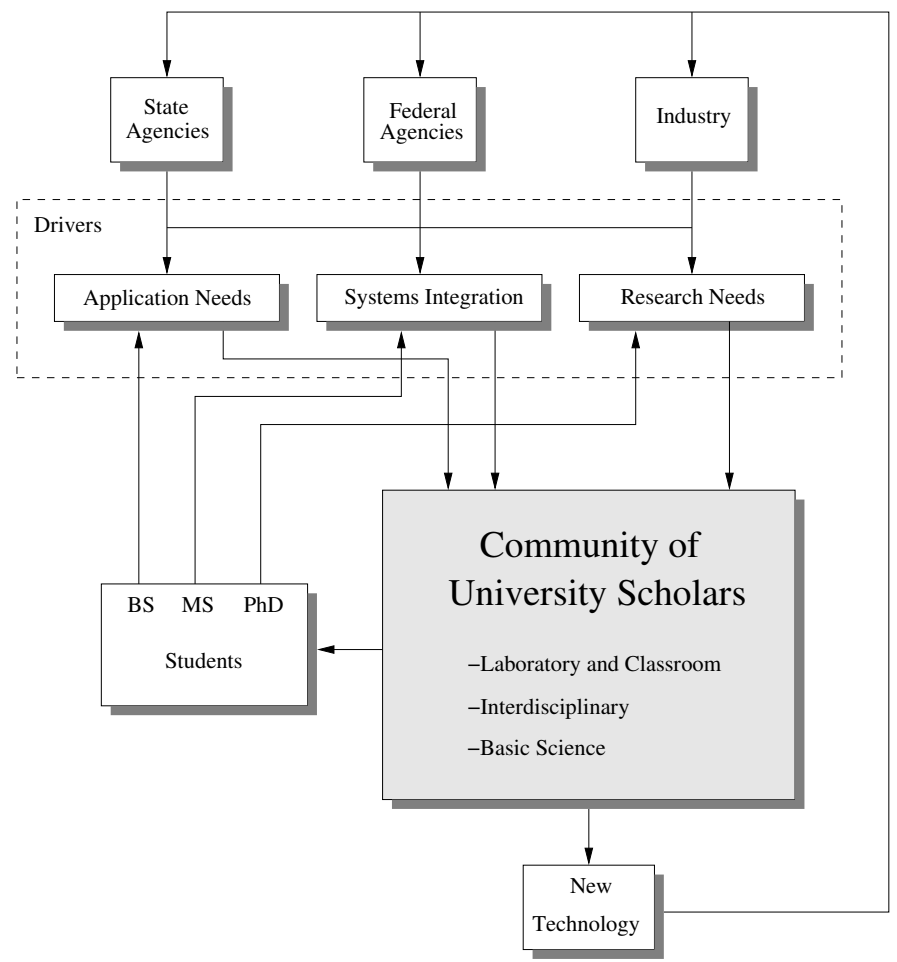

Figure 1: Students gain valuable hands-on knowledge from a rich diversity of projects. By employing a teamwork effort with their professors and project sponsors, a very satisfying community of scholars is developed that provides innovative technical solutions and cross-training for professors and students alike.

laborative research projects at the NWRT. The proposed laboratory/teaching program will provide abundant opportunities for individuals that may concurrently assume responsibilities as researchers, educators, and students. The NWRT will facilitate joint efforts that infuse education with the excitement of discovery and enrich research through a diversity of learning perspectives.

\section{Integrated Interdiscliplinary Curriculum}

The project is truly a cross-disciplinary effort between the School of Meteorology and the School of Electrical and Computer Engineering. This cross-fertilization between engineering and meteorology is also exemplified in efforts currently underway at our university to develop the cross-disciplinary Weather Radar and Instrumentation Curriculum. The investigators, along with other colleagues at the university, have developed a unique curriculum which provides an in-depth education in meteorological radar and instrumentation with emphasis 
on a hands-on experience. This aspect of the program directly addresses a major concern among leaders in the meteorological community about the lack of expertise in the use of instrumentation [12]. The following figure provides a brief overview of the course sequence developed for this new curriculum, which shows the logical progression from undergraduate to graduate education. The classroom exposure to radar theory, with supportive real radar data projects, is greatly enhancing the educational experience of the students and will more thoroughly prepare them for active scientific careers.

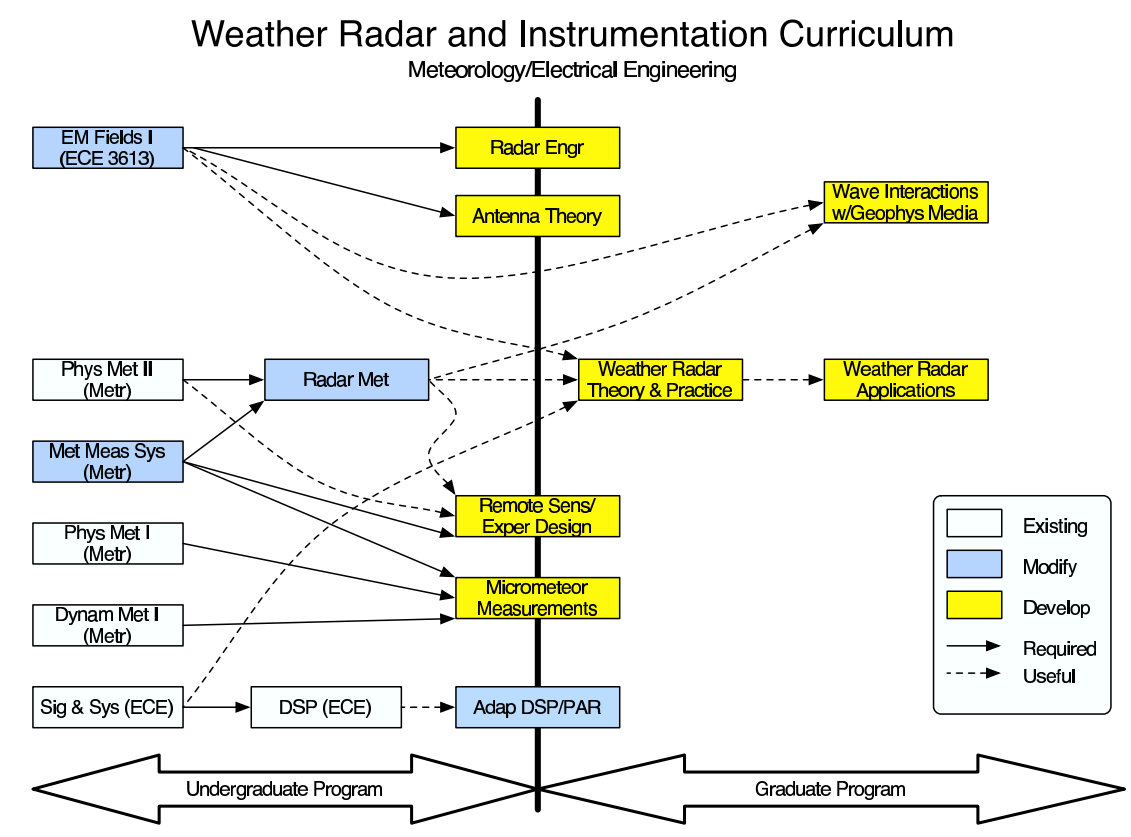

Figure 2: The new laboratory activities leverage the momentum of an interdisciplinary teaching program that the authors currently have in place with other faculty. This figure provides a summary of courses, which comprise the weather radar and instrumentation curriculum. Currently, ten professors are associated with these courses that span both the undergraduate and graduate curricula in two departments.

Supporting the curriculum is a comprehensive outreach program. The principal investigators are partnering with the Oklahoma Climatological Survey (OCS) to adapt and implement project materials directly to K-12 teachers via the OCS EarthStorm outreach program. Established in 1992, the EarthStorm project (NSF TPE-9155306, and currently funded by the State of Oklahoma) has provided over 250 Oklahoma schools with the materials and requisite education to apply real-time environmental data in support of math, science, and engineering curricula. For over a decade, OCS has implemented weather curricula as part of laboratory activities for undergraduate students (NSF DUE -9981098), conducted annual summer content institutes for K-12 teachers (State of Oklahoma funded), as well as hosted dozens of K-12 student science fairs (funded by US Department of Energy). Broadly, the authors are disseminating content-rich materials to OCS for adaptation into the math and science curricula at the 250 K-12 schools (primarily middle schools) served by OCS outreach programs. These materials will enhance teacher and student knowledge of fundamental atmospheric and engineering topics. Specifically, weather radar content has been integrated into the OCS summer content institutes for middle school teachers. Furthermore, K-12 teachers participating in the summer 
content institutes will be paired with our peer teachers in a mentorship arrangement to aid in the implementation of weather radar content into the middle school classrooms (peer teachers are discussed later). During the summer workshops, the middle school outreach will focus on basic radar fundamentals formulated around weather radar applications. In the summer of 2005, the OCS facilitated the weeklong EarthStorm Summer Institute in July. Approximately 48 teachers for 6th through 8th grade from around the state and surrounding states signed up to attend. During the preceding fall semester, our peer teachers took the courses offered by the team of professors. Then, during the spring semester, the peer teachers prepared laboratory exercises for the workshop during the summer. Finally, our assessment expert took survey data.

\section{New Courses Developed:}

The philosophy of the courses that have been developed was oriented around the adaptation of a nationally known radar program at Colorado State University (CSU). The CSU-CHILL radar facility is funded by the National Science Foundation and the State of Colorado for the purpose of supporting the atmospheric research community by providing data and evaluating experimental techniques in remote sensing of the atmosphere (http://chill.colostate.edu). Carried further, their Virtual CHILL (VCHILL) concept at the CSU radar facility allows remotely located users to access realtime displays and control the operation of the radar over the Internet. Thus, the goal of the VCHILL initiative is to provide the educational experience of radar at a remote location, without compromising the features of an on-site radar console. Thus, to complete the cycle of innovation, whose annulus begins with the pioneering work at CSU, extending through the state-of-the-art radar facility at the NWRT - our efforts have offered the development of a revolutionary laboratory and coursework curriculum that coincides with the interdisciplinary development and integration of the School of Electrical and Computer Engineering and the School of Meteorology. A suite of courses has been developed, and where prudent, the courses were cross listed between the two departments; for instance, Radar Engineering is cross listed, while Electromagnetic Fields is not. Cross listing has been shown to strengthen the bonds of these types of collaborative efforts, while welcoming, attracting, and retaining students $[13,14,15]$. These courses were supported by specific laboratory exercises.

- Introduction to Meteorology introduces students to important phenomena and physical processes that occur in the Earth's atmosphere. Through lectures and laboratory exercises, students will learn the basic concepts and tools that are used to study atmospheric problems.

- Electromagnetic Fields is an existing course in which modifications are currently being explored and implemented which include plane wave propagation, polarization, reflection, and an introduction to radiation/antennas - all related to the study of the atmosphere.

- Introduction to Measurement Systems introduces the physical principles of meteorological sensors, discusses static and dynamic performance concepts, and explores the concepts of meteorological measurement systems. 
- Radar Engineering introduces various radar system designs and their applications with an emphasis on weather radar. Radar system architecture and their functionalities and limitations of subsystems are discussed.

- Radar Meteorology is an established course (that has been updated with new laboratory experiments) that develops the quantitative relationships between a radar and its target - i.e., interpretation of the data.

- Weather Radar Theory and Practice is a new course (with supporting laboratory experiments) that concentrates on the radar equation, time domain algorithms, and spectral analysis.

- Adaptive Digital Signal and Array Processing is a new course devoted to the theory of adaptive algorithms for aircraft tracking and the discovery of interesting weather targets.

- Remote Sensing and Experimental Design is an upcoming class devoted to the placement of various remote and in-situ sensors for significant studies in the field.

Table 1: Layout of The Interdisciplinary Classes

\begin{tabular}{|l|c|c|c|c|c|}
\hline \multicolumn{1}{|c|}{ Course } & Dept & Level & Semester & Status & Cross-list \\
\hline \hline Intro to Meteorology & METR & soph & fall & new & no \\
\hline Electromagnetic Fields & ECE & jr & spring & refined & no \\
\hline Intro to Measurement Systems & METR & jr & fall & refined & no \\
\hline Radar Engineering & ECE & sr & fall & new & yes \\
\hline Radar Meteorology & METR & sr & spring & refined & soon \\
\hline Weather Radar Theory/Practice & METR & sr & fall & new & yes \\
\hline Adaptive DSP \& Array & ECE & sr & fall & new & soon \\
\hline Remote Sensing/Experimental Design & METR & sr & fall & upcoming & soon \\
\hline
\end{tabular}

Interaction between classes and assessment: The program was carefully tailored to fit within the current degree plans of both schools. Prerequisites have been carefully observed to welcome and retain students. Special content for the new Introduction to Meteorology course was developed and served as a point of entry into the weather radar curriculum. Next, students are required to take Electromagnetic Fields or Introduction to Measurement Systems. Subsequent to this, students can enroll in Radar Engineering and/or Radar Meteorology. These classes were taught and coordinated to ensure student success. Finally, students take the in-depth Adaptive Digital Signal/Array Processing or the Weather Radar Theory/Practice class - which culminate all previous learning, concentrate on deep projects, and serve as a fantastic spring board into our advanced graduate level programs in both schools. These were always offered in the fall. Two out-of-department assessment experts were responsible for carefully developing assessment instruments for each course. These specially designed lengthy surveys were based on the learning objectives of the course syllabi. 


\section{Hands-on Laboratory Exercises:}

Teaching modules have proven to be an effective means of introducing new material into an existing curriculum, without adding new courses [16, 17]. Moreover, the development of modules allows for the easy implementation at other institutions of learning [18]. There are many advantages to encapsulating a focused amount of material in a modular fashion, and modules were the educational cornerstone of DARPA's \$150M Rapid Prototyping of Application Specific Signal Processors program [19]. At our university, the new modules, instruction, and assessment have been designed in accordance with the ABET Criteria 3 parts (a)-(k) [20]. They have also been carefully constructed to facilitate their adoption at other institutions. A few sample modules from selected courses are given below. Within the sequence of courses, the learning of scientific phenomena, such as interesting atmospheric events, is greatly enhanced when students are allowed to make measurements and construct mathematical models that govern their behavior [21]. Several teamwork-oriented laboratory modules will be integrated into each of the four courses. These modules will be organized around four themes: 1.) data collection: developing different scanning patterns, 2.) data processing: computing and enhanced algorithms to extract weather information from the raw radar data, 3.) data display: placing the composite weather information on a user-friendly computer display, 4.) data interpretation: scientific understanding and discovery of the displayed data - this includes the locations and dynamics of storms, precipitation, tornados, downbursts, and the like. Each of the four items complement and build upon one another - thus solidifying the interaction between the courses. These hands-on laboratory modules are similar to the CSU experiments $[22,23,24]$. In terms of the course outlines, the unifying themes that integrate the courses will be: (i) introduction and detailed study of the Science of weather radar, (ii) the modern-day Technology of displaying and interpreting weather phenomena on a conventional computer screen, (iii) the Engineering of data acquisition and analysis techniques, and (iv) the Mathematics of weather radar processing.

Facilities: Students will continue to have an unprecedented opportunity to take advantage of a unique federal, private, state and academic partnership that has been formed for the development of the phased array radar technology at the NWRT - a student experience similar to the national resource at CSU. Eight participants contributed to the installation of the new radar, including: NOAA's National Severe Storms Laboratory and National Weather Service Radar Operations Center, Lockheed Martin, U.S. Navy, Federal Aviation Administration, and BCI, Inc. The project very favorable institutional support, since: 1.) this effort is complementary to its research mission, 2.) it has the resolute potential to affect approximately 840 students across two departments, and 3.) it produces highly sought after students (by industry and graduate programs). Within the Engineering Center on campus that houses the School of Electrical and Computer Engineering, a special classroom has been dedicated for this teaching program. This classroom known as the "Undergraduate Weather Radar Computing Laboratory" for use by all of the courses and community building activities. At the current time, contemporary infrastructure in the laboratory supports our mission: 12 new computers, a new server, and associated equipment to pipe the radar's data into this laboratory on the main campus - closely following the current CSU implementation, which consists of a "client server model", where a server runs at the radar facility and the client program operates at remote locations. Looking forward, the flexibility of this laboratory setting allows students at 
other universities to duplicate our course, since the data can be readily downloaded from the Internet. At the time of this writing, Java scripts are currently being prepared at the NWRT for this operation. Moreover, for most people, precipitation is the single most important discriminator between a correct and incorrect forecast [25].

At the current time, student activities are numerous. Computing algorithms are studied and implemented that convert radar data from the phased array radar into environmental measurements known as spectral moments - very similar to previous researchers associated with conventional rotating weather radars [26, 27, 28]. Spectral moments (reflectivity, radial velocity, and spectrum width) are the essential, required radar meteorological measurements that are used to make decisions about cloud locations, storms, rain fall, tornados, downbursts, hail and other interesting weather phenomena. Microbursts are strong downbursts of air from evolving rain-clouds which can develop in a matter of minutes and cause windshear. These present hazards for aircraft, especially when taking off or landing. These windshears or strong downbursts are especially dangerous to aircraft [29, 30, 31]. Through appropriate configuration of the phased array radar at the NWRT, it can be designed to provide this windshear information $[29,30,31,32,33]$. Detecting windshear is a classic problem for aircraft, but our work will also provide an image of the atmosphere surrounding the radar. This will provide aircraft and other vehicles in the future an ability to make reasonable short term weather forecasts and improved situational awareness. Prior to collecting the weather data, it is imperative that the transmit waveforms of the phased array antenna be properly designed for this activity [30, 32, 33], which does include pulse compression. Similar to current work on the conventionally rotating WSR-88D, staggered pulse repetition times (PRTs) will also be explored to improve the data quality and increased scan rates [34]. In the dual-use mode, of collecting weather information while tracking targets of homeland interest, the scan strategy of the radar will need to be devised to accommodate both targets - that is, an adaptive multiplexing operation that visits each target differently. With respect to weather, the radar does not have to radiate the entire volume every scan or sweep of the beams. Weather targets are much larger than aircraft and move at a slower rate. Updates every minute is adequate. The problem for the radar is that weather targets can have a very small reflectivity and the algorithms will require good Doppler resolution [35]. This requires longer dwells where data is collected.

\section{Undergraduate Peer Teachers:}

We define a peer teacher to be someone who: 1.) is a very energetic and motivated student that will serve as a teaching assistant, 2.) is a member of our engineering research program and radar curriculum, and 3.) is a diverse undergraduate student. A rich populous of broad students will be enhanced with the assistance of the Diversity Coordinator within the Multicultural Engineering Program (MEP) at our university. This person is responsible for 354 minority students within our college and will coordinate the hiring of the peer teachers. The judicious use of peer teachers has been shown to be a highly effective means to motivate and retain undergraduates in engineering [36, 37, 38]. The peer teachers will have three primary duties: 1.) assist the instructor in the class/laboratory during periods of team-work activity, 2.) host tutoring sessions for fellow students outside of class/laboratory time, and 3.) assist with K-12 outreach (described later). Since the peer teachers are close in age 
to the students and highly familiar with NWRT's research plan, they will be in a position to add significant value to the integrated program. During the first few semesters of our project, we have found that approximately $54 \%$ of the students who served as a peer teacher also join our graduate program. Students were organized into groups of teams and teamwork will be stressed [39]-[42]. The teammate selection will be carefully coordinated by the course instructor to ensure cross-disciplinary students. Teamwork has also been shown to increase retention $[43,44]$, and learning is enhanced when it resembles a team effort rather than a solo race [45]. Moreover, learning is achieved by individuals who are intrinsically tied to others as social beings, interacting as competitors or collaborators, constraining or supporting the learning process, and able to enhance learning through cooperation and sharing [46]. Various teachers have found that team-based learning can be especially helpful in classes with a high level of student diversity [47]. Team-based learning creates conditions in which people who are very different from one another learn that they need to work together and that they can work together. They find ways to make their differences an asset rather than a liability [47].

\section{Merging Pedagogical and Scientific Learning Goals}

Unifying THEME: the pedagogical goals and the scientific goals shall be merged together with a taxonomy of significant learning. As originally defined by Bloom and his associates, a taxonomy is described as a "classification," so the well-known taxonomy of learning objectives is an attempt (within the behavioral paradigm) to classify forms and levels of learning [51]. Since the pioneering work of Bloom, other taxonomies have been developed. The most often cited ones include work by Anderson and Krathwohl [52]; Wiggins and McTighe [53]; and Fink [50]. Here, our proposed effort follows the philosophies of Fink, as his work provides a methodology that comes from an understanding that individuals and organizations involved in higher education are expressing a need for important kinds of learning that do not emerge easily from the Bloom taxonomy, for example: learning communication skills, character, tolerance, the ability to adapt to change, etc. As described in [50] and cited in countless other works, including [56, 57, 58, 59], Fink's Taxonomy of Significant Learning is oriented around the idea that each kind of learning is interactive, as illustrated in Figure 3 [50]. This means that each kind of learning can stimulate other kinds of learning. As each element of the model is included in the classroom, the more each element will support their counterparts, thus increasing the significance of the learning experience [50]. Fink's Taxonomy of Significant Learning is oriented around the idea that each kind of learning is interactive, as illustrated in Figure 3 [50]. This means that each kind of learning can stimulate other kinds of learning. As each element of the model is included in the classroom, the more each element will support their counterparts, thus increasing the significance of the learning experience [50].

\section{Evaluation Plan}

The courses/laboratory modules supported by this proposal will teach students the knowledge, skills and interest necessary to transform radar data into meaningful interpretations of weather, based on information displays generated by the students themselves. Activities are included that will 1.) increase the number of K-12 students coming to college with an interest in weather radar and 2.) enable other universities to easily adopt similar programs. The evaluation plan is designed to assess how well the courses and other activities achieve their 


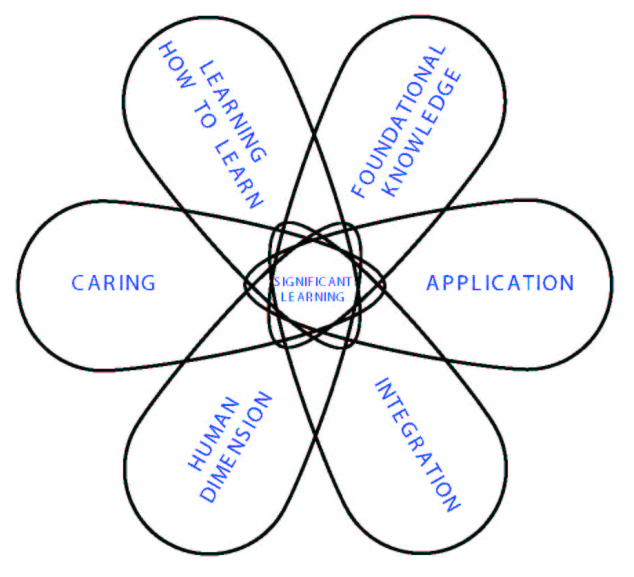

Figure 3: Interactive nature of significant learning [50].

intended purposes $[48,54,55]$. This will involve the development of questionnaires, assessment instruments, and interview protocols for each project goal, see Table 2 .

Table 2: Evaluation Plan of the Meteorology and Engineering Effort

\begin{tabular}{|c|c|c|}
\hline Project Goals & Sources of Information & Specific Criteria \\
\hline $\begin{array}{l}\text { 1. Develop student knowl- } \\
\text { edge and skills related to } \\
\text { all phases of creating so- } \\
\text { phisticated weather radar. } \\
\text { 2. Develop sufficient stu- } \\
\text { dent interest that they en- } \\
\text { roll in additional courses in } \\
\text { the program. }\end{array}$ & $\begin{array}{l}\text { - Gather baseline data on } \\
\text { entering students. } \\
\text { - Assess their knowledge, } \\
\text { skills, and interest at the } \\
\text { end of each of the courses. } \\
\text { - Monitor enrollment in } \\
\text { subsequent courses. }\end{array}$ & $\begin{array}{l}\text { - } 85 \% \text { of all students will } \\
\text { have the necessary knowl- } \\
\text { edge and skills. } \\
\text { - } 60 \% \text { will enroll in subse- } \\
\text { quent courses in the pro- } \\
\text { gram. }\end{array}$ \\
\hline $\begin{array}{l}\text { 3. Increase the number of } \\
\text { middle school students in- } \\
\text { terested in weather science } \\
\text { when they enter college. }\end{array}$ & $\begin{array}{l}\text { - Collect survey data from } \\
\text { middle school students } \\
\text { who participate in special } \\
\text { programs. }\end{array}$ & $\begin{array}{l}\text { - } 70 \% \text { of the participating } \\
\text { students will "Agree" or } \\
\text { "Strongly Agree" that they } \\
\text { are interested in studying } \\
\text { weather science when they } \\
\text { enter college. }\end{array}$ \\
\hline $\begin{array}{l}\text { 4. Encourage relevant de- } \\
\text { partments in other univer- } \\
\text { sities to implement similar } \\
\text { programs in weather radar. }\end{array}$ & $\begin{array}{l}\text { - Informal expressions of } \\
\text { interest at conference pre- } \\
\text { sentations. } \\
\text { - Information from depart- } \\
\text { ments indicating they ac- } \\
\text { tually plan to implement } \\
\text { similar programs. }\end{array}$ & $\begin{array}{l}\text { - By the end of the third } \\
\text { year of this project, de- } \\
\text { partments in at least } 5 \\
\text { other universities will have } \\
\text { implemented (or be plan- } \\
\text { ning the implementation } \\
\text { of) similar programs. }\end{array}$ \\
\hline
\end{tabular}


Timeline for the Evaluation Activities: During the first year of the project, questionnaires for the baseline data will be developed. In addition, the project evaluator will work with the course teachers to (a) identify all major learning goals (e.g., knowledge, application) and then (b) develop assessment procedures for appraising each kind of learning. At the end of each course, two tasks were completed: student learning was assessed by the written methods and the professors were interviewed. The latter information was used to determine such things as how satisfied the teachers were with the level of student learning and whether the work load involved in teaching the course was within acceptable limits.

\section{Outreach Assessment}

Teachers participating in EarthStorm completed project evaluations describing what they learned from the project, the most and least helpful aspects, further information they would like to learn, concerns and suggestions, and appropriate changes. These evaluations were in the form of an extensive, written questionnaire. It is noted that the Earthstorm workshop had a duration of several days and that our materials were only a part of this comprehensive program. The assessment below summarizes the activities, while also shining light on our radar tutorials. Information learned: Respondents were overwhelmed by the wealth of knowledge they gained from EarthStorm 2005. Respondents indicated having a new understanding of the intricacies involved in weather; participants did not previously understand the number of variables affecting weather. In addition, participants valued the information presented concerning radar data analysis and interpretation. EarthStorm presented the past, present, and future of weather radar as well as potential applications of radar data. Respondents expressed appreciation for the thorough discussion of technical applications including WeatherScope, the EarthStorm web page, and online radar data. Helpful aspects: EarthStorm participants found the thorough lesson plans and step-by-step instruction for classroom activities to be very useful. Several participants identified the comprehensive WeatherScope tutorial as the most useful aspect of EarthStorm. A majority of respondents identified detailed computer instruction as the most helpful feature. In order to improve EarthStorm content, survey respondents were asked to share the least helpful parts of EarthStorm. Several teachers believed that the portion of EarthStorm concerning inquiry teaching was unnecessary. Further learning: EarthStorm generated an interest in gaining additional knowledge about weather and weather radar. Several teachers expressed curiosity about the fundamental aspects of weather; teachers wanted to learn more about basic weather elements, climate, forecasting, severe weather, tornadoes, and hurricanes. While respondents appreciated technical aspects of EarthStorm, they wanted more material covering simplified meteorology. Appreciation, concerns, suggestions: Teachers expressed overwhelming appreciation of the friendly, knowledgeable, professional, and helpful staff. The variety of speakers provided a well-rounded week. Most respondents enjoyed the radar facility tour and weather balloon launch - similar to the events at the annual Weather Festival. The EarthStorm participants were thankful for the impressive computer lab used throughout the project; participants could work individually on computer-based labs. Teachers appreciated the staff and service at the hotel on campus. It was clear that participants were impressed with EarthStorm material, presentation, organization, and staff.

\section{Appendix: Example Laboratory Studies}


In a recent paper by Shuman and his colleagues [71], they campaign for the philosophy that "One of the primary methods created to help integrate team learning into the engineering classroom is the development of formal curricular modules that could be used by various faculty planning to have students work on team projects." In fact, universities in remote locations, such as in Puerto Rico, have relied on teaching modules for especially difficult courses [61]. As such, compelling evidence exists that indicates that student do have a positive reaction to teaching modules. As noted in [62], survey data indicated a positive student reaction to this type instructional material. In addition, such modules have also been a stimulus to increased retention for women in engineering [60]. By observing other successful pedagogical programs in the US, such as the Clark School of Engineering at the University of Maryland and their modular team training program that was funded by the National Science Foundation, we can assess their strengths, while avoiding known pitfalls - thus helping to complete the cycle of innovation. The goal of their "Building Engineering Student Team Effectiveness and Management Systems (BESTEAMS)" was to provide a team curriculum that can be easily adopted by engineering faculty from various schools and at different levels of the undergraduate curriculum [72]. Several of our laboratory exercises are given below.

Statistical Properties of Weather Radar Data Module: This laboratory exercise is taught as part of Weather Radar Theory and Practice, also known as METR 5673 or ECE 4973/5283. As eloquently articulated in the passages of the book titled Engineer of the 2020 [66], students will be expected to have a better understanding of the "natural world" and although natural disasters are beyond man's control, man's ability to predict them and adapt accordingly are essential to minimize impact. In fact, about one-third of the nation's $\$ 10$ trillion economy is sensitive to climate variability and weather $[64,63,65]$. Predicting these natural disasters heavily depends, in part, on making decisions based on measured radar data. As such, experiential learning is a highly effective means to convey new concepts to students $[49,69,70]$; moreover, the voluminous amounts of data generated by a weather radar lends itself to this teaching strategy quite well. Expecting students to convert radar signals based on electromagnetic measurements into meaningful graphs and plots on a computer screen is something that is best learned by the students - by doing it themselves after the traditional classroom lecture and with small amounts of strategic guidance from the instructor. In this module, students investigated the NWRT data from June 2005. In particular, students prepared power estimates and these reflectivity factor values were used to estimate rainfall rate associated with severe weather. In addition, the students were required to study the statistical nature of these real data and compare to the theory presented in class. Based on [68], Figure 4 depicts one example of the collected and processed data from our hands-on experiments in June.

Multi-Function Module: On a national basis, airport capacity has increased by only 1 percent in the past 10 years, while air traffic increased 37 percent during that time, as reported by the American Society of Civil Engineers [67]. It is clear that America's infrastructure is aging. Providing discipline specific solutions will be extremely costly. However, by working together, a diverse group of scientists and engineers can develop the individual radars can be used in a multi-function capacity to provide both weather and target tracking data. This strategic alliance greatly reduces costs, while providing enormous benefits to the public. Figure 5 depicts the team's aircraft tracking measurements using the NWRT. Uncooperative or unfriendly targets may experience erratic behavior on an undocumented flight plan. 

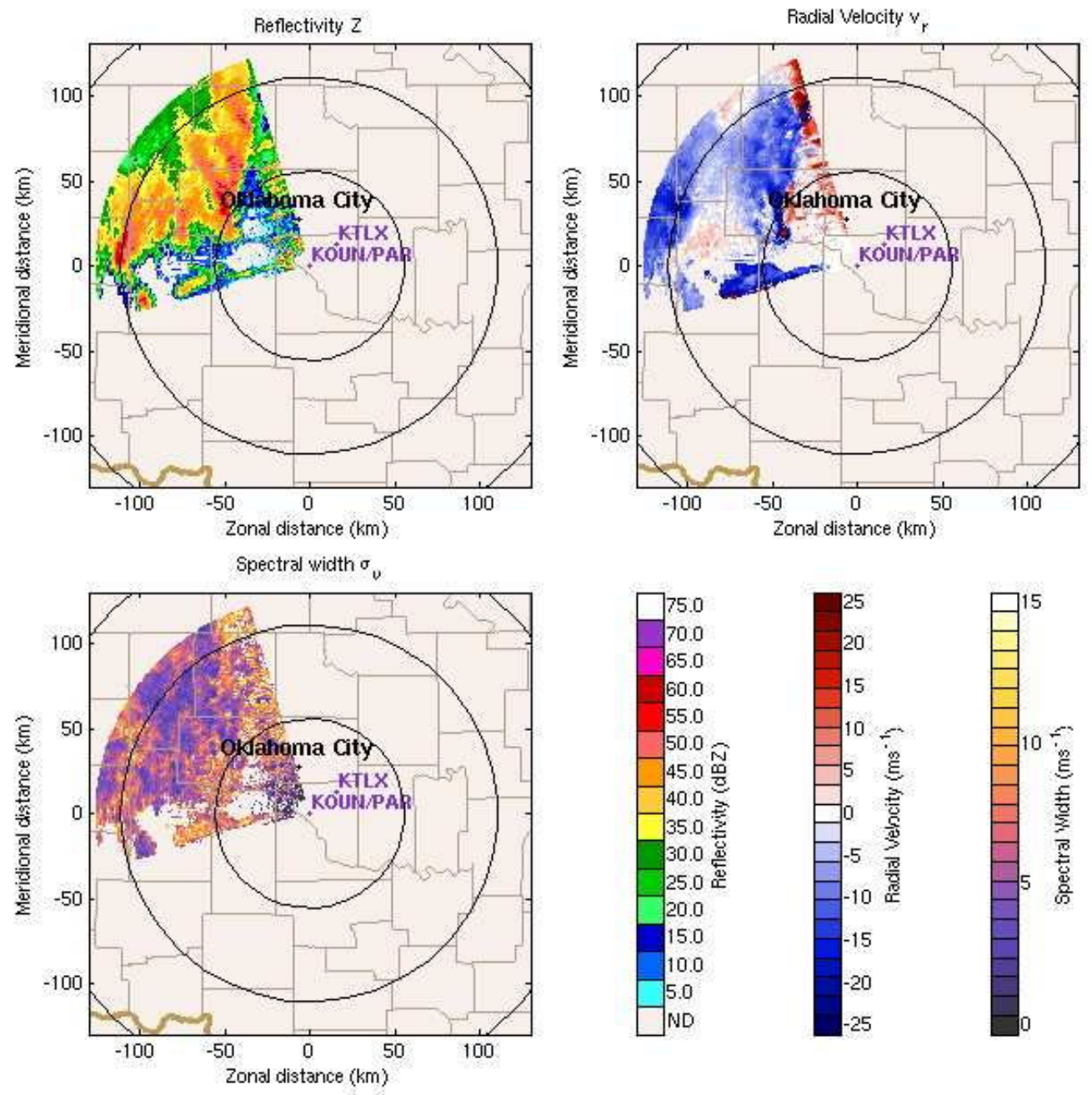

Figure 4: As the radar illuminates the atmosphere, raindrops will reflect energy back towards the radar. This reflectivity data can be used to determine the location of storms. By making additional calculations on the reflectivity data, students can make important estimates of rainfall rates. This is especially helpful for early-warning systems providing flash flood notifications. 

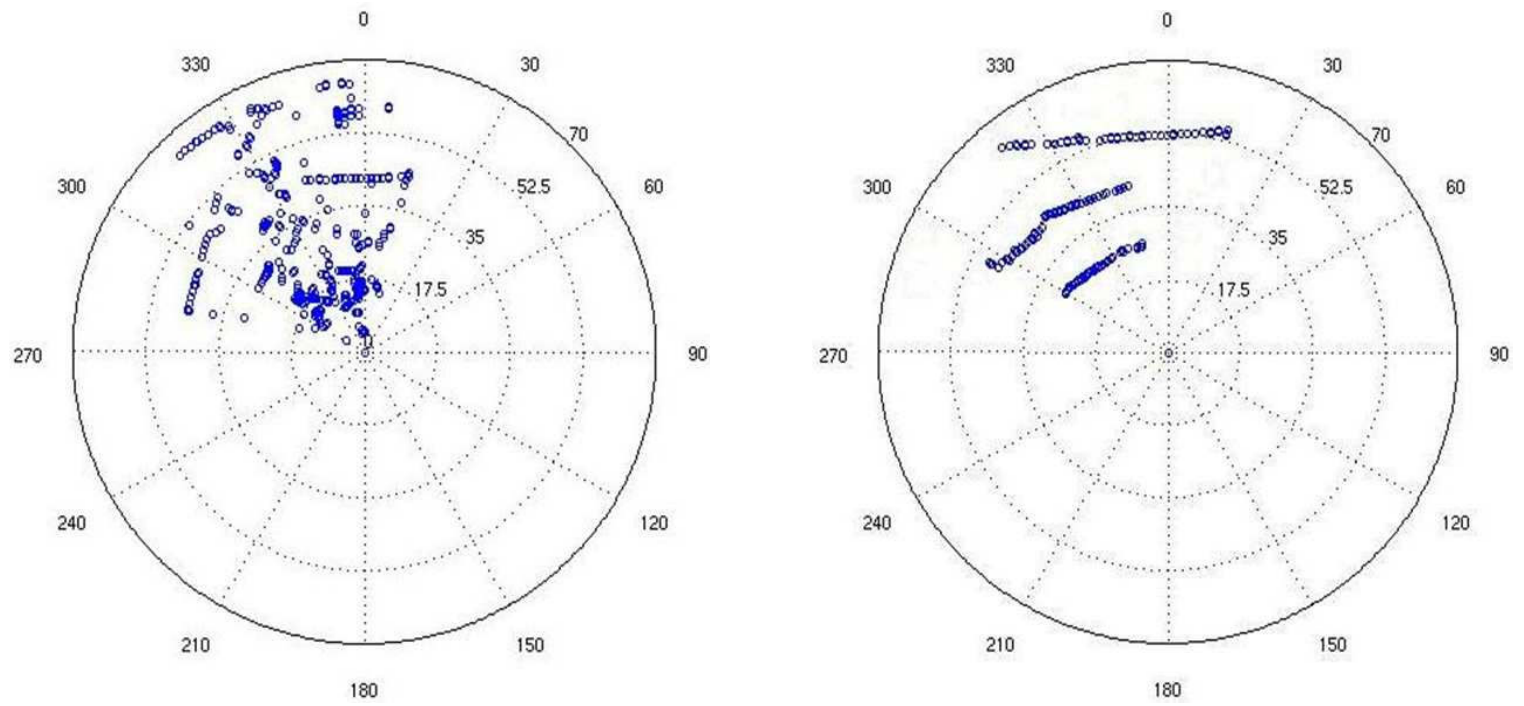

Figure 5: Left: For the first time, this figure depicts a airport traffic at a major international airport and vicinity, as measured by the NWRT. This data was taken on September 15, 2005. Here, detections were made within a 90 degree sector, looking towards the airport. The set of concentric circles denote distances in units of kilometers away from the radar. Right: This figure depicts the paths of specific planes at the airport as measured by the NWRT on September 19, 2005. In addition to weather phenomenon, students are exposed to techniques for developing specific search volumes and detecting smaller targets of homeland interest, tracking these targets, and formulating hypothesis about the moving target's future trajectory. 


\section{References}

[1] National Research Council Committee on Weather Technology Beyond NEXRAD, 2002: Weather Technology Beyond NEXRAD. Washington, DC: National Academy Press.

[2] National Oceanic and Atmospheric Administration, New Priorities of the 21st Century, www.noaa.gov, pp. 1-23. March, 2003.

[3] National Research Council, Making Climate Forecasts. Washington, DC: National Academy Press, 1999.

[4] National Science and Technology Council, Ensuring a Strong U.S. Scientific Technical and Engineering Workforce in the 21st Century, Washington, DC: Office of Science and Technology Policy. 2000.

[5] National Commission on Mathematics and Science Teaching for the 21st Century, Before It's Too Late, Washington, DC: U.S. Department of Education. 2000. Available at http://www.ed.gov/americacounts/glenn

[6] T. Camp, "The Incredible Shrinking Pipeline," Communications of the ACM, vol. 40, no. 10, pp. 103-110, 1997.

[7] Boyer Commission on Educating Undergraduates in the Research University. Shirley Strum Kenny, Chair, University of Stony Brook. Reinventing Undergraduate Education: Three Years After the Boyer Report, 2002.

[8] National Science Foundation, "Course, Curriculum, and Laboratory Improvement," www.nsf.gov, NSF 03-558, 2003.

[9] B. Moskal, D. Lasich, N. Middleton, "Improving the Retention of Women and Minorities through Research Experience, Mentoring and Financial Assistance," Proceedings of the American Society for Engineering Education Annual Conference, session 1392, pp. 1-11, 2001.

[10] D. Niemeier, R. Boulanger, P. Bayly, S. Schmid, K. Muraleetharan, and A. Barros, "Integration of engineering education and research: perspectives from the NSF civil and mechanical systems 1998 CAREER workshop," Journal of Engineering Education, pp. 199-202, April, 2001.

[11] A. Jenkins, R. Breen, R. Lindsay, and A. Brew, Reshaping Teaching in Higher Education : Linking Teaching and Research, London, Kogan Page, and Educational Development Association. Distributed by Stylus in the USA. 2003.

[12] E. Takle, "University instruction in observational techniques: survey responses," Bulletin of the American Meterological Society, vol. 81, pp. 1319-1325, 2000.

[13] A. Kenimer, J. Morgan, "Building Community through Clustered Courses," Proceedings of the ASEE Annual Conference, 2002.

[14] P. Ryadby Backer and S. Bates, "Introduction to product design and innovation: a cross-disciplinary miniCurriculum," Proceedings of the ASEE Annual Conference, pp. 1$10,2005$. 
[15] J. Frolik and T. Keller, "Wireless sensor networks: an interdisciplinary topic for freshman design," Proceedings of the ASEE Annual Conference, pp. 1-7, 2005.

[16] W. Perry, V. Barocas, and D. Clough, "Implementing Computational Methods into Classes throughout the Undergraduate Chemical Engineering Curriculum," Session 3613, pp. 1-9. ASEE, 1999.

[17] B. Mauldin, T. Reed-Rhoads, "Measuring Cognitive and Affective Performance in a Statistics Course that uses Online Computer Statistics Modules," pp. 1-22, Session 1665, ASEE 2001.

[18] C. Hendrickson, N. Conway-Schempf, H. Matthews, F. McMichael "Green Design Educational Modules and Case Studies," pp. 1-17, Session 2451, ASEE 2000.

[19] V. Madisetti, A. Gadient, J. Stinson, J. Aylor, R. Klenke, H. Carter, T. Egolf, M. Salinas, T. Taylor, "DARPA's Digital System Design Curriculum and Peer-Reviewed Educational Infrastructure," ASEE Annual Conference \& Exposition, Session 1232, pp. 1-15, 1997.

[20] "Engineering Criteria 2000," Accreditation Board for Engineering and Technology. http://www.abet.org/EAC/eac2000.html, December 1998.

[21] G. Nelson, "Science literacy for all in the 21st century," Educational Leadership, vol. 57, no. 2, October, 1999.

[22] V. Chandrasekar, D. Brunkow, A. Jayasumana, S. Bolen, "Development of a virtual radar environment" International Geoscience and Remote Sensing Symposium, vol. 6, pp. 2599-2601. July, 2001.

[23] K. Gojara, S. Bolen, V. Chandrasekar, "Undergraduate research on remote sensing at Colorado State University," International Geoscience and Remote Sensing Symposium, vol. 6, pp. 2757-2758. July, 2001.

[24] V. Bringi and V. Chandrasekar, "The CSU-CHILL fully polarimetric s-band weather radar facility: Providing research experience to undergraduates," International Geoscience and Remote Sensing Symposium, vol. 2, pp. 954-956. July, 1997.

[25] J. Tribbia, "Weather Prediction", chapter 1 in Economic Value of Weather and Climate Forecasts, R. Katz and A. Murphy, editors. Cambridge University Press, 1997.

[26] R. Doviak and S. Dusan, Doppler Radar and Weather Observations, 2nd edition, San Diego: Academic Press, 1993.

[27] R. Rinehart, Radar from Meteorologists, 4th edition, Columbia, MO: Rinehart Press, 2004.

[28] V. Bringi and V. Chandrasekar, Polarimetric Doppler Weather Radar: Principles and Applications, 1st edition, Cambridge University Press, 2001.

[29] G. Stimson, Airborne Radar, 2nd Edition, Scitech Publishing: New Jersey, 1998. 
[30] K. Lai, I. Longstaff, G. Callaghan, .Super-fast scanning technique for phased array weather radar applications,. IEE Proceedings of Radar, Sonar and Navigation, Volume 151, Issue 5, pp. 271-379, Oct 2004.

[31] F. Nathanson, Radar Design Principles, McGraw-Hill: New York, 1991.

[32] M. Skolnick, Introduction to Radar Systems, 3rd edition, New York: McGraw Hill, 2002.

[33] R. Keeler and C. Hwang, "Pulse compression for weather radar,.. IEEE International Radar Conference, pp. 529-535, May 1995.

[34] R. Ice, G. McGehee, R. Rhoton, D. Saxion, D. Warde, R. Guenther, D. Sirmans, D. Rachel, .Radar Operations Center (ROC) evaluation of new signal processing techniques for the WSR-88D,. 21st International Conference on Interactive Information Processing Systems for Meteorology, Oceanography, and Hydrology, P1.4., January, 2005.

[35] L. Buckler, .Dual-use air traffic control radar,. Proceedings of the IEEE Radar Conference, pp. 26-31, May 1998.

[36] J. Morgan, A. Kenimer, T. Kohutek, J. Rinehart, M. Lee, "Peer Teacher From an Instructor's Perspective," Proceedings of the Frontiers in Education Conference, 2002.

[37] R. Caso, et. al., "A Systemic Change Model in Engineering Education and its Relevance for Women" Proceedings of the ASEE Annual Conference, 2002.

[38] A. Garcia, G. Keller, A. McHenry, F. Begay, "Enhancing Underrepresented Student Opportunities Through Faculty Mentoring and Peer Interactions," Proceedings of the ASEE Annual Conference, 1998.

[39] L. Michaelsen, W. Watson, J. Cragin, and L. Fink, "Team learning: A potential solution to the problem of large classes," Exchange: The Organizational Behavior Teaching Journal, vol. 7, pp. 13-22, 1982.

[40] L. Michaelsen, "Team learning: A comprehensive approach for harnessing the power of small groups in higher education," To Improve the Academy, vol. 11, pp. 107-122, 1992.

[41] L. Michaelsen, L. Fink, A. Knight, "Designing effective group activities: lessons for classroom teaching and faculty development," To Improve the Academy, vol. 16, pp. 373398, 1997.

[42] Seat, E. and S. M. Lord, "Enabling Effective Engineering Teams: A program for Effective Interaction Skills," J. Eng. Educ., vol. 88, no. 4, pp. 385-390. 1999.

[43] Keeping Students in Higher Education: Successful Practices and Strategies for Retention by Adele S. Newson-Horst. Copyright 1998-2002 by Society for College and University Planning

[44] William Koolsbergen, "Approaching Diversity: Some Classroom Strategies for Learning Communities," Peer Review, Summer/Fall Edition, 2001. 
[45] Chickering and Gamon, "Seven Principles of Good Practice in Undergraduate Education." (revisions: 1987, 1991, 1999). First published in the March, 1987 edition of the AAHE Bulletin.

[46] S. Engelkemeyer and S. Brown. "Powerful partnerships: A shared responsibility for learning." American Association for Higer Education Bulletin, pp. 10-12., October, 1998.

[47] L. Michaelsen, A. Knight, and L. Fink (editors), Team-Based Learning: A Transformative Use of Small Groups in College Teaching, Sterling, VA: Stylus Publishing, 2003.

[48] J. Bransford, A. Brown, and R. Cocking, Editors How People Learn: brain, mind, experience, and school, National Research Council. Washington, DC: National Academy Press, 2000.

[49] D. Kolb, Experiential Learning: Experience as the Source of Learning and Development, Englewood Cliffs, N.J.: Prentice-Hall, 1984.

[50] L. Fink, Creating Significant Learning Experiences, San Francisco, CA: Jossey-Bass, 2003.

[51] B. Bloom, ed., Taxonomy of Educational Objectives, the Classification of Educational Goals - Handbook I: Cognitive Domain, New York: McKay, 1956.

[52] L. Anderson and D. Krathwohl (eds.), A Taxonomy for Learning, Teaching and Assessing: A Revision of Bloom's Taxonomy of Educational Objectives, New York: Longman, 2001.

[53] G. Wiggins, Educative Assessment: Designing Assessments to Inform and Improve Student Performance, San Francisco, California: Jossey-Bass, 1998.

[54] T. Angelo and P. Cross, Classroom Assessment Techniques, 2nd ed., San Francisco, CA: Jossey-Bass, 1993.

[55] B. Bloom, J. Hastings, and G. Madaus, Handbook of Formative and Summative Evaluation of Student Learning, New York: McGraw-Hill, 1971.

[56] K. Smith, S. Sheppard, D. Johnson, and R. Johnson, Journal of Engineering Education, ASEE, vol. 94, no. 1, pp. 87-101, January 2005.

[57] L. D. Fink, S. Ambrose, D. Wheeler, Journal of Engineering Education, ASEE, vol. 94, no. 1, pp. 185-194, January 2005.

[58] T. Brumm, A. Ellertson, D. Fisher, S. Mickelson, "Practicing omega: addressing learning outcomes in an on-line case simulation," Session 1408, Proceeding for the American Society for Engineering Education (ASEE) Annual Conference and Exposition, 2004.

[59] E. Audette and R. Bennett, "Addressing the need for engineering educators in higher education: a proposal and an associated curriculum," Session 2555, Proceeding for the American Society for Engineering Education (ASEE) Annual Conference and Exposition, 2004.

[60] S. Bartolomei and S. Cruz-Pol, "An Electrical Engineering Module for Women in Engineering," Proceeding for the 2003 American Society for Engineering Education (ASEE) Annual Conference and Exposition, Nashville, TN, 2003. 
[61] J. Colom and S. Cruz Pol, "Remote Sensing Modules to Increase Interest in Traditional Difficult Courses," IGARSS 2001 Symposium, Sydney, Australia, 2001.

[62] R. Pimmel, R. Leland, and H. Stern, "Student Evaluation of Instructional Modules on EC 2000 Criteria 3 (a)-(k) Skills," 2002 ASEE Annual Conference and Exposition. Montreal, Quebec. Session 2532, pp. 1-11.

[63] Bureau of Economic Analysis, 2002: GDP by Industry. www. bea. gov /bea /dn2 /gpo. htm

[64] National Research Council, The Atmospheric Sciences Entering the Twenty First Century. National Academy Press, 1998.

[65] J. Dutton, "Opportunities and priorities in a new era for weather and climate services," Bulletin of American Meteorolgy Society, vol. 83, pp. 1303-1311. 2002.

[66] National Academy of Engineering, The Engineer of 2020. National Academy Press, 2004.

[67] American Society of Civil Engineers, Report Card for America's Infrastructure, www. asce. org, 2003.

[68] R. Palmer, Weather Radar Theory, class notes, University of Oklahoma, fall 2005.

[69] M. Bailey and J. Chambers, "Using the experiential learning model to transform an engineering thermodynamics course," ASEE/IEEE Frontiers in Education Conference, session T2F, pp. 1-6, 2004.

[70] J. Bruce, J. Harden, and R. Reese, "Cooperative and progressive design experience for embedded systems," IEEE Transactions on Education, vol. 47, no. 1, pp. 83-92, Feb 2004.

[71] L. Shuman, M. Besterfield-Sacre, J. McGourty, "The ABET 'professional skills' - can they be taught? can they be assessed?," Journal of Engineering Education, ASEE, vol. 94, no. 1, pp. 41-55, January 2005.

[72] L. Schmidt, J. Schmidt, C. Colbeck, D. Bigio, P. Smith, and L. Harper, "Engineering students and training in teamwork: how effective?" (CD) Proceedings, 2003 American Society for Engineering Education Conference. 